\title{
THE NATURE OF THE Co-C BOND CLEAVAGE PROCESSES IN METHYLCOB(II)ALAMIN AND ADENOSYLCOB(III)ALAMIN
}

\author{
Tudor Spataru ${ }^{\mathrm{a}^{*}}$, Francisco Fernandez \\ ${ }^{a}$ Department of Chemistry, Columbia University, New York, New York 10027, United States \\ ${ }^{b}$ Natural Sciences Department, Hostos Community College, 500 Grand Concourse, Bronx, New York 10451, United States \\ "email: ts2407@columbia.edu; phone: (1) -212-854-1080; fax: (1)-212-932-1289
}

\section{In Memory of the Academician Constantin Turta}

\begin{abstract}
Unfortunately, there are still significant disagreements between experimental and theoretical data of rate constants, energy barriers for $\mathrm{Co}-\mathrm{C}$ bond cleavage process and coordination numbers of vitamin $\mathrm{B}_{12}$ coenzyme species in spite of the remarkable efforts done by research community. Therefore, no grounded mechanisms for Co-C vitamin $\mathrm{B}_{12}$ coenzyme bond breaking process and subsequent reactions have been found up to now. The influence of the mixing orbitals e.g. Pseudo-Jahn-Teller and similar effects on the reactions paths of bond-cleavage mechanisms of vitamin $\mathrm{B}_{12}$ co-factors must be taken into account by utilizing multi-reference methods, in particular multiconfigurational self-consistent field (MCSCF) method. Then, the change in total energy along the normal coordinate $Q$ for the stretching mode including Co-C and Co-N bonds in vitamin $\mathrm{B}_{12}$ cofactors is expected due to a "vibronic" coupling term, which couples an excited state and ground state by a second order derivative potential-energy operator. The strong state mixing effect is expected to lead to low energy barriers and to $\mathrm{Co}-\mathrm{C}$ and $\mathrm{Co}-\mathrm{N}$ axial bond cleavage events in agreement with experimental data. Afterward, the updated mechanisms of vitamin $\mathrm{B}_{12}$ bio-processes can be determined.
\end{abstract}

Keywords: vitamin $\mathrm{B}_{12}$, mechanism, bio-catalysis, Pseudo-Jahn-Teller effect, DFT, MCSCF.

Received: December 2015/ Revised final: February 2016/ Accepted: February 2016

\section{Introduction}

Vitamin $B_{12}$ cofactor is one of eight $B$ vitamins and is involved in mammalian cellular metabolism, influencing amino acid and DNA synthesis [1] and hematopoiesis. The best known human physiological function of vitamin $\mathrm{B}_{12}$ is its role in promoting normal health in the brain and nervous system. Vitamin $\mathrm{B}_{12}$ anemia can cause such neurologic dysfunction as weakness, fatigue, light-headedness, rapid heartbeat, rapid breathing, pale skin color, bruising, and bleeding (including bleeding gums). The more severe vitamin $\mathrm{B}_{12}$ anemia dysfunctions are characterized by tingling or numbness of the fingers and toes, difficulty walking, mood changes, depression, memory loss, disorientation and, in most severe cases, dementia [2]. Vitamin $\mathrm{B}_{12}$ deficiency has even been considered in playing a role in the development of Alzheimer's disease [3-7].

The vitamin $B_{12}$ cofactor contains a cobalt atom surrounded by an equatorial corrin ring. Covalently linked to the central atom is a dimethylbenzimidazole that occupies one of the axial coordination positions. The opposite coordinate is available for several ligands in bio-medium or in solution; however, known biologically active structures containing adenosyl- or methyl have been considered most often (Figure 1).
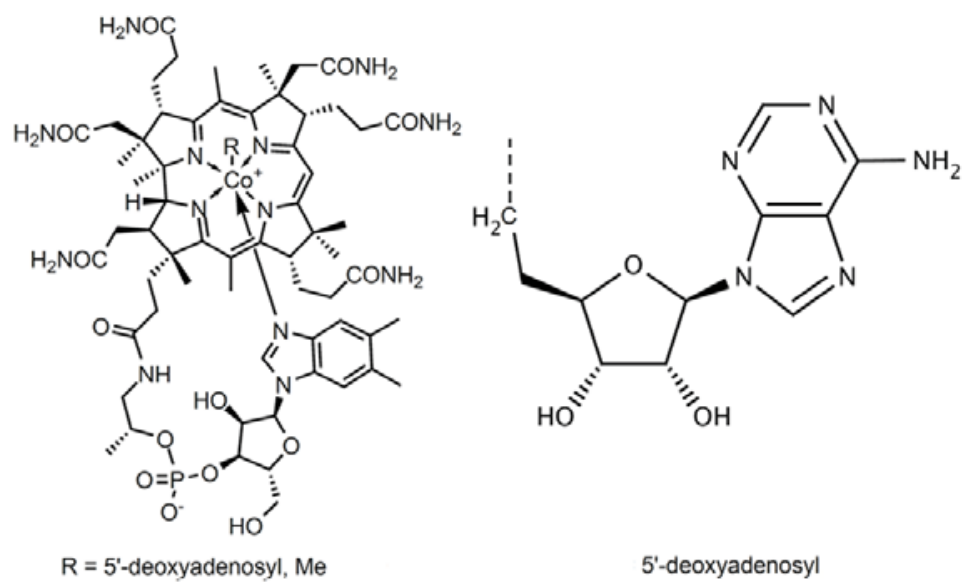

Figure 1. The structure of vitamin $B_{12}$ cofactor (left side) and of 5-deoxyadenosyl ligand (right side) with coordinating dash bond [8-10]. 
Vitamin $B_{12}$ is known to participate in at least two types of enzyme-catalyzed reactions [8-10] in the human body: a) isomerase rearrangements with participation of the adenosylcobalamin form of vitamin $\mathrm{B}_{12}$; $\mathrm{b}$ ) methyltransferases with participation of the methylcobalamin form of vitamin $B_{12}$. To date, human consumption of the various vitamin $B_{12}$ varieties and their mechanisms of action in the human body are still under study. The best form of vitamin $B_{12}$ to be recommended to patients is still not fully established in the medical community [6-10]. Moreover, the recommended dosage of vitamin $B_{12}$ varies from one author to another [3-7]. One of the more controversial areas of research regarding the vitamin $\mathrm{B}_{12}$ mechanism is its activation that starts with $\mathrm{Co}-\mathrm{C}$ bond cleavage under influence of electron transfer and/or substrate influence. There is little agreement between experimental and theoretical data in spite of a significant amount of research on this problem. The mechanism of vitamin $\mathrm{B}_{12}$ must be updated with correct theoretical and experimental data that is in agreement with each other.

This review is dedicated to a better understanding of the chemistry involved with $\mathrm{B}_{12}$ bio-catalysis in searching of a firmer foundation upon which we can treat the various forms of anemia and neurologic dysfunction diseases associated with vitamin $\mathrm{B}_{12}$.

\section{The mechanisms of methylcobalamin and adenosylcobalamin activation}

Vitamin $B_{12}$ and its derivatives have received considerable attention for their use in organic chemistry [11-19]. The cobalamin cofactor plays an integral role in methyl transfer by donating methyl groups to homocysteine and accepting them from $\mathrm{CH}_{3}-\mathrm{H}_{4}$ folate [20-22]. The biological reactions catalyzed by cobalamin-dependent methionine synthase generally include as a primary turnover the enzyme-bound cobalamin prosthetic group cycling between methylcob(III)alamin and cob(I)alamin forms. All corrinoid-dependent methyl transferases bind the corriniod cofactor with displacement of the dimethylbenzimidazole ligand: in most cases the side chain of histidine residue (Figure 2) from the enzyme is a new ligand [11,23-28].
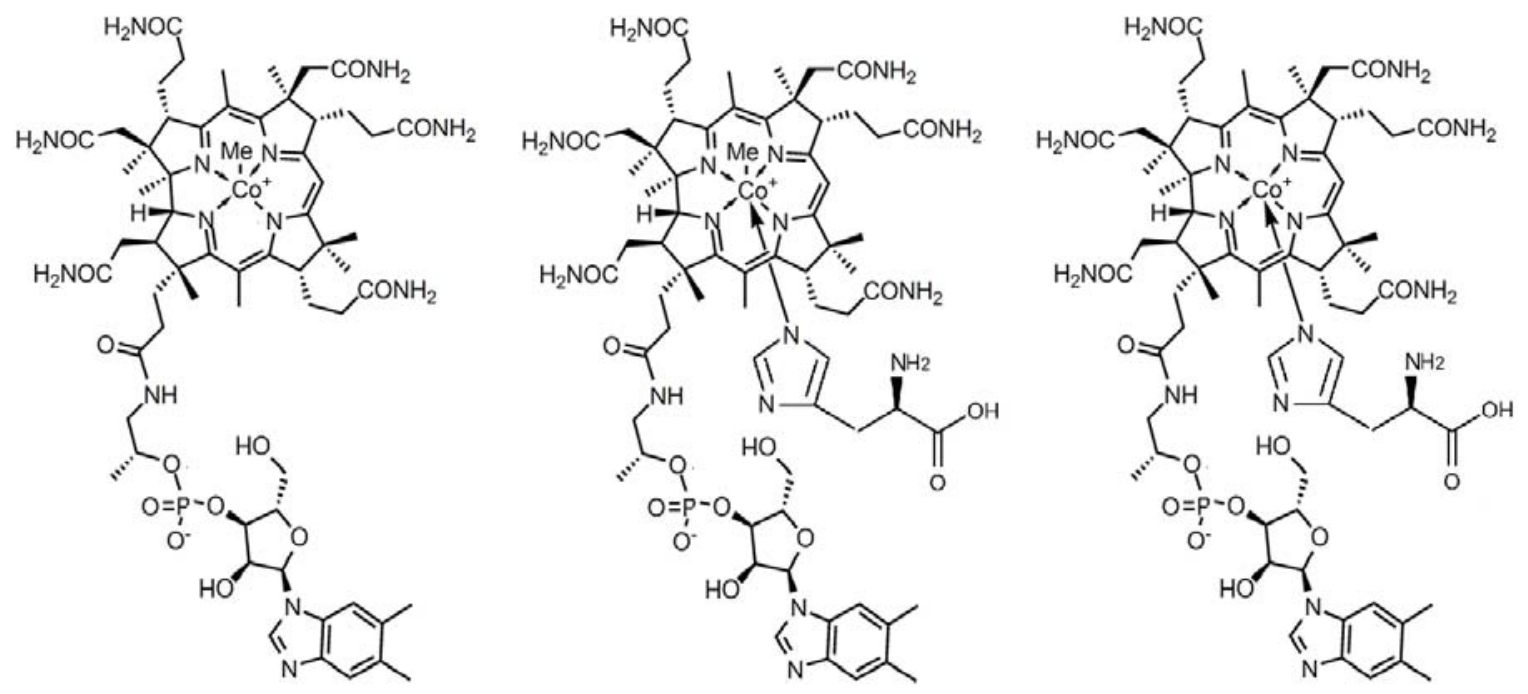

Figure 2. The schemes of the methylcobalamin coenzyme common structures found by X-ray diffractions [11,23-28].

Adenosylcobalamin is the cofactor of several enzymatic processes [29-37], such as melanoma cell adhesion molecule (MCAM), glutamate mutase, methyleneglutaratemutase, class II ribonucleoside triphosphate reductase, ethanolamine ammonia lysase, and diol-glycerol dehydratase. A common feature of these enzymes is that the Co-C bond of adenosylcobalamin is cleaved homolytically to initiate the reaction, giving rise to a five-coordinate cob(II)alamin and an adenosyl radical. Measurements of the rate constant for cob(II)alamin formation demonstrate that the enzyme increases the rate of homolysis of the $\mathrm{Co}-\mathrm{C}$ bond by $10^{12}$-fold both for $\mathrm{B}_{12}$ - dependent methylmalonyl-Co-A mutase and adenosylcobalamin-dependent glutamate mutases [33,34]. Finally, we should point out the differences between the initial stages in methyl- and adenosyl-dependent mutases considering the Co-C cleavage process. As it is depicted in Figure 3: (a) the methylcobalamin-dependent methionine synthase generally includes as a primary turnover the cycling between Co(III) methylcobalamin and cob(I)alamin, which allows the heterolytic Co-C cleavage process, while in the adenosyl-cobalamin-dependent mutases the Co-C bond of adenosylcobalamin is cleaved homolytically, giving rise to a five-coordinate cob(II)alamin and an adenosyl radical; (b) the association of the substrate and adenosyl-ligand during the $\mathrm{Co}-\mathrm{C}$ cleavage process in adenosylcobalamin dependent mutases has been proved by various experimental data including X-ray diffraction results [35-37], while such effect is totally absent in studies regarding methylcobalamindependent mutases. 


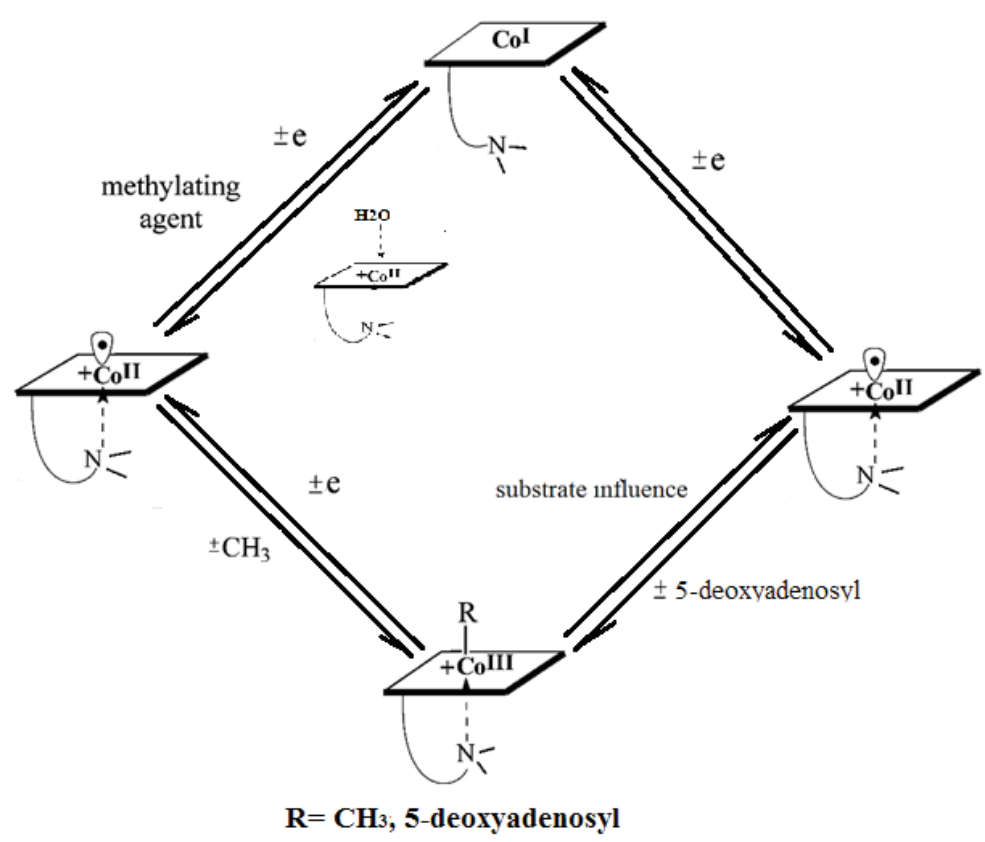

Figure 3. The generalized scheme of the methylcobalamin and adenosylcobalamin coenzyme turnovers [38-67].

The Co-C cleavage and electron transfer processes have been studied by different methods such as electrochemistry [38-40], thermo- [41] or photochemistry [42-46] of methylcobalamin Co(III) by a significant number of researchers. As a result, many triggering factors of $\mathrm{Co}-\mathrm{C}$ bond breaking have been considered and various mechanistic mechanisms of the Co-C cleavage process have been proposed. Many researchers have considered axial ligand transinfluence, steric effects, structural strain, protein influence, in addition to others [47-58] as determinant factors in the Co-C cleavage process. The hydrogen transfer from the substrate to 5-deoxysdenosyl ligand has also been considered as a triggering factor of the $\mathrm{Co}-\mathrm{C}$ bond breaking [59-67]. These suggestions have been largely unconfirmed by subsequent data. Only substrate influence on the Co-C cleavage process in the case of the adenosylcobalamin vitamin $\mathrm{B}_{12}$ species has been confirmed [35-37]. New approaches and new strategies are needed for the analysis of this challenging biological phenomenon.

The reductive activation mechanism of methylcobalamin has been studied by D. Lexa and J.M. Savèant using cyclic voltammetry of two similar compounds, methylcobalamine (base-on species) and methylcobalamide (base-off species) in DMF-1-propanol [38]. The methylcobalamide compound shows a single irreversible cathodic wave at low sweep rates corresponding to the reductive cleavage of the cobalt-carbon bond. At the slow scan rate of $0.3 \mathrm{~V} / \mathrm{s}$ the cyclic voltammetry $(\mathrm{CV})$ of methylcobalamin showed no return wave; however, as the scan rate increased to $10 \mathrm{~V} / \mathrm{s}$ and above at $-20{ }^{\circ} \mathrm{C}$, a return wave appeared which allowed Lexa and Savéant [38] to propose the multistep electrochemical mechanism (Figure 4). Upon raising the sweep rate the cathodic wave becomes progressively reversible, clearly showing the existence of a one-electron intermediate before cleavage of the cobalt-carbon bond.

$$
\begin{aligned}
\mathrm{R}-\mathrm{Cbl}+\mathrm{e}^{-} & \rightleftharpoons[\mathrm{R}-\mathrm{Cbl}]^{-}{ }_{\text {base-on }} \rightarrow \mathrm{R} \cdot+\mathrm{B}_{12 \mathrm{~s}}{ }^{-} \\
\downarrow \uparrow & \\
{[\mathrm{R}-\mathrm{Cbl}]^{-}{ }_{\text {base-off }} } & \rightarrow \mathrm{R} \cdot+\mathrm{B}_{12 \mathrm{~s}}{ }^{-}
\end{aligned}
$$

Figure 4. The scheme of the methylcobalamin reductive electrochemical mechanism [38,39].

Here, $\mathbf{R}$ is a methyl group.

We $[39,40]$ and Martin \& Finke [41] have determined similar methylcobalamine reductive mechanisms.

Unfortunately, the above mechanism is not fully supported by theory when considering DFT calculation data $[39,40]$. Additionally, the generally accepted methylcobalamin reductive mechanism (Figures 2 and 3 ), based on various experimental methods including X-ray diffraction, does not fit exactly with the electrochemistry based methylcobalamin reductive mechanism (Figure 4). It is obvious that experimental and theoretical data do not combine to provide a clear understanding of vitamin $\mathrm{B}_{12}$ activation in the human body. Deeper and more detailed studies using adequate and modern methods should be performed to ensure a sound basis of the mechanism of activation of vitamin $\mathrm{B}_{12}$. 
Density Functional Theory (DFT) and Quantum Mechanics/ Molecular Mechanics (QM/MM) calculations on vitamin $B_{12}$ cofactors

We $[39,40]$ and others have performed DFT calculations of vitamin $B_{12}$ models [68-100]. Consequently, various properties have been studied, including electron densities and reduction potentials determination [69,76,88,91,96], the comparison of DFT and CASSCF electronic structure data of truncated models of methylcobalamin species $[70,71,74,81,85]$, the influence of various factors on the Co-C bond forming and cleavage in methyl- and 5-adenosylcobalamin models [68,72-76,79,80,83,84,89,90,92,94,97,99,100], and excited states, spectroscopy and photo-dissociation analysis of vitamin $\mathrm{B}_{12}$ species $[78,82,86,87,93,95,98]$. We used DFT calculations on Me-Cbl models to calculate total energy as a function of $\mathrm{Co}-\mathrm{C}$ bond distance as the bond is stretched [39]. The generally used base-on model of $\mathrm{R}-\mathrm{Cbl}(\mathrm{III})\left(\mathrm{R}=\mathrm{CH}_{3}\right)$ includes the full corrin ring with all side-chain groups replaced by hydrogen atoms and with the dimethylbenzimidazole base ligand replaced by benzimidazole (or imidazole), as it is shown in Figure 5.

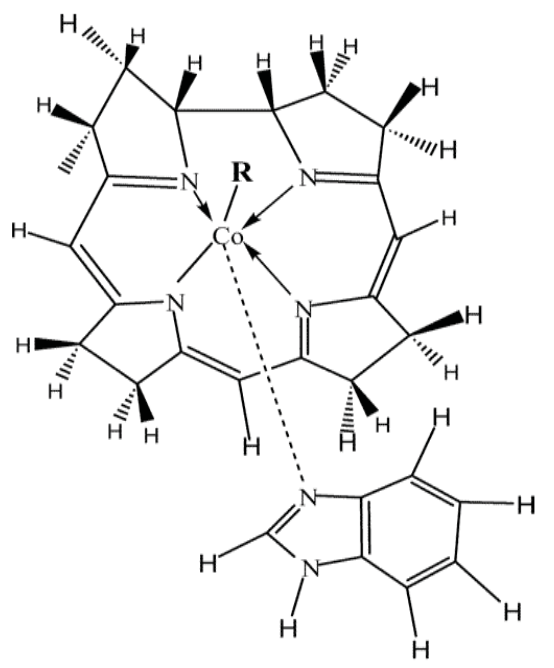

Figure 5. The methylcobalamin model used in DFT calculations $[39,106]$.

This approach was taken for construction of base-on and base-off models of positively charged $\mathrm{CH} 3-\mathrm{Co}(\mathrm{III})^{+}$ and likewise for the neutral reduced CH3-Co(II) [41]. The optimized DFT geometry for all four species at B3LYP/ LANL2DZ theory level showed nearly the same equilibrium C-Co bond distance of around 2.00A. The dissociation total energy barrier heights from single-point calculations for both the base-on and base-off CH3-Co(III) ${ }^{+}$models were almost the same, ca. $2.8 \mathrm{eV}$ (Figure 6); however, for the base-on $\mathrm{CH} 3-\mathrm{Co}(\mathrm{II})$ model, this dissociation energy was much lower, ca. $1.6 \mathrm{eV}$, and for the base-off species, even lower, ca. $1.1 \mathrm{eV}$.

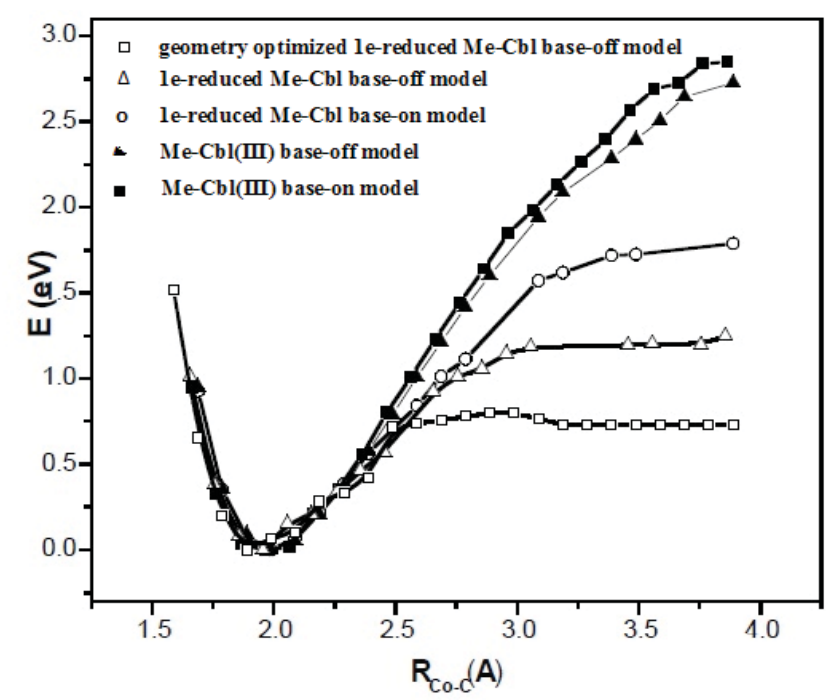

Figure 6. Total B3LYP/LANL2DZ energy (eV) as a function of Co-C bond distance (Å) for methylcobalamin model compounds for different redox species and axial base conditions.

The energy of all curves has been aligned at the minimum [39,106]. 
Despite the progress made by the research community on the theoretical explanation of vitamin $\mathrm{B}_{12}$ cofactor reaction, there are still significant disagreements of theoretical results with experimental data. Thus, our calculation of the total energy with geometry optimization at each constrained C-Co bond length for the base-off CH3-Co(II) model gives the lowest energy barrier for C-Co bond breaking (value of $0.7 \mathrm{eV}$, Figure 6) $[39,106]$. However, even with this barrier, a kinetic calculation shows that fast bond cleavage is improbable. Furthermore, the energy barrier of the Co-C bond breaking is much higher for base-on compared to the base-off species $[39,68,106]$. Our estimations show that the energy barrier of the geometry optimized 1e-reduced base-on specie is higher by about $0.5 \mathrm{eV}$ compared to the energy barrier of the geometry optimized 1e-reduced base-off specie (see Figure 7 for single points calculations). Therefore, according to DFT calculations the rate constant of Co-C bond cleavage has a much lower value for base-on species compared to the rate constant of similar reactions for base-off species. This enters a flagrant contradiction with the experimental data, which demonstrates that the reaction rate constant of $\mathrm{Co}-\mathrm{C}$ bond breaking is much higher in base-on species compared with the same reaction rate constant for base-off species [38]. Moreover, base-off methylcob(II)alamin compound cannot be considered in $\mathrm{Co}-\mathrm{C}$ bond cleavage reaction of bio-reactions since is predicting a four coordinate vitamin $B_{12}$ specie immediately after a Co-C bond cleavage of methylcobalamin compound $[39,68,106]$. Instead, several experimental results show that methylco(II)calamine cofactor is five coordinate $[23-28,101,102]$ immediately after Co-C bond cleavage.

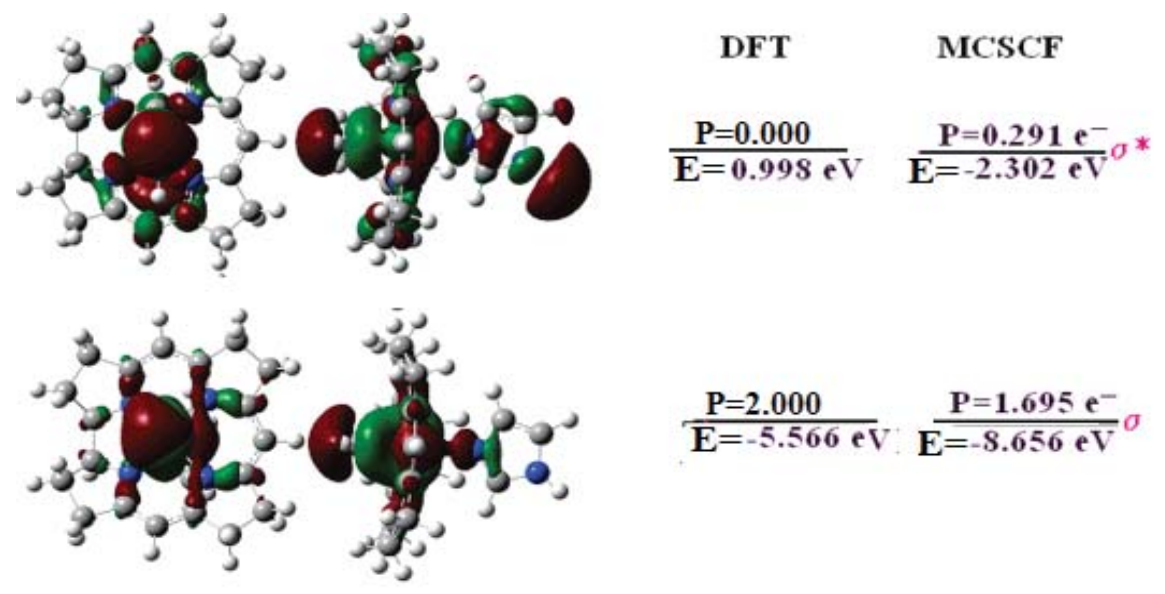

Figure 7. The methylco(II)balamin DFT-B3LYP/LANDL2DZ and MCSCF (9,7) (CASSCF) surfaces, energies and populations of $\sigma$ and $\sigma^{*}$ MO $[39,106]$.

Another unfortunate discrepancy is that theoretical results support the existence of a six-coordinate methylcobal(II)aminecofactor with dimethybenzimidazol ligand bonded to cobalt ion. Such a six-coordinate specie, which has not been mentioned by any experiment up to now, has a clear minimum (Figure 6) of total energy in the DFT method $[39,106]$, testifying in favor of its stability. Finally, no theoretical model gave the expected Co-C bond cleavage energy barrier for the methylcob(II)alamin models. The closest to the desired results up to now have been obtained byusing QM/MM and DFT methods, which, unfortunately, still give greater than expected barriers for either, base-on or base-off species, equal to $8.3 \mathrm{kcal} / \mathrm{mol}, 10.5 \mathrm{kcal} / \mathrm{mol}$, and $7.3 \mathrm{kcal} / \mathrm{mol}$, respectively [72,73,80] (in vivo Co-C cleavage process is supposed to run without barrier). Finally, we conclude that there is an evident requirement to improve the models used in theoretical calculations and the use of more advanced theoretical treatments for the study of vitamin $\mathrm{B}_{12}$ activation.

\section{The multi-configuration effects in methylcob(II)alamin and its Co-C bond cleavage}

Although, the study of the in-situ electron transfer in reduced cobalamin compounds is quite a challenging problem, the real catalytic process and electronic transfer in cobalamin-dependent enzymes are even more complicated. For instance, the electron transfer problem includes also the role of mixed valence feredoxin compounds, which participate in electron transfer [103-105] to a series of biosystems and participate into turn-over of cobalamin-dependent enzyme processes. The mixed valence feredoxin compounds are a common example of vibronic (Jahn-Teller) systems in chemistry, due to their symmetry. On the other hand, our recent electron structure studies show that the HOMOLUMO and Co-C $\sigma-\sigma^{*} \mathrm{MO}$ gaps are significantly smaller in the $\mathrm{Co}$ (II) methylcobalamin system compared with $\mathrm{Co}$ (III) methylcobalamin, proving that the orbital mixing is effective [106]. Therefore, the activation of Co-C bond cleavage in cobalamin bio-chemistry must be treated as an orbital mixing process and the Co(II) methylcobalamin system cannot be treated correctly by DFT methods [107], as it is a Pseudo-Jahn-Teller system [108]. Such orbital mixing leads to 
a fractional population of the $\sigma$ and $\sigma^{*}$ orbitals, including also several bonding occupied and antibonding unoccupied orbitals [106]. The $\sigma^{*}$ orbital, which is situated significantly above $\pi^{*}$ SOMO, is coupled strongly with formal $\sigma$. As a result, the energy of these two $\sigma$ and $\sigma^{*}$ molecular orbitals change significantly during the geometry optimization (Figure 7). The population of the $\sigma^{*}$ antibonding orbital increase and the population of the $\sigma$ bonding orbital decrease, thus "weakening" the force constants along the $\mathrm{Co}-\mathrm{C}$ and $\mathrm{Co}-\mathrm{N}$ bonds. This strong state mixing (similar to the pseudoJahn-Teller effect) leads to an increase in the Co-C bond and $\mathrm{Co}-\mathrm{N}_{\mathrm{ax}}$ bond lengths with about $0.2 \AA$ for base-off Co(II) methylcobalamin model compounds and base-on Co(II) methylcobalamin model compounds (Figure 8). This coupling explains also the much lower Co-C bond dissociation enthalpy and much faster bond cleavage rate for the one-electron reduced methylcobalamin radical anion compared to the methylcobalamin neutral system. Such calculations like MCSCF with strong orbital coupling are extremely sensitive to any perturbation. We have obtained a similar result for $\mathrm{Co}-\mathrm{C}$ bond cleavage in the case of the $\mathrm{Co}$ (III) adenosylcobalamin system under the perturbation (slight interaction influence) of the enzyme substrate. Therefore, it is reasonable to consider the influence of the substrate as a perturbation factor of the electronic structure influencing the $\mathrm{Co}-\mathrm{C}$ and $\mathrm{Co}-\mathrm{N}$ bond breaking for vitamin $\mathrm{B}_{12}$ cofactors species. We believe that this concept can be generalized for electron transfer or for substrate influence and subsequent bond cleavage in important biological systems.
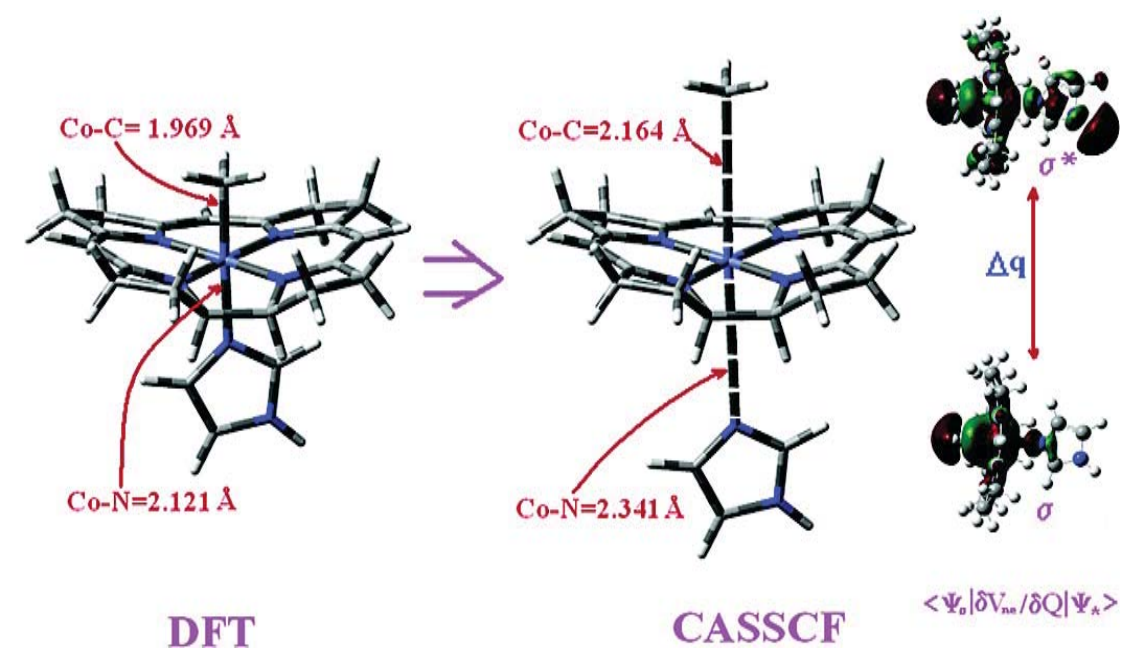

\section{Figure 8. The cartoon of $\sigma$ and $\sigma^{*}$ MO coupling influence on axial $\mathrm{Co}-\mathrm{C}$ and $\mathrm{Co}-\mathrm{N}$ bonds of one electron reduced methylcobalamin $[39,106]$.}

Generally speaking, the MCSCF method, which takes into account multi-configuration interactions, is among the most accurate methods of electronic structure calculations. Unfortunately, the number of electrons and orbitals taken into consideration in our previous calculation [106] are not in harmony with the needs for totally accurate calculation results of the MCSCF method with a complete active space that can be compared with experimental data and that can serve as the basis to develop a precise and reliable mechanism of activation for vitamin $\mathrm{B}_{12}$. In the computing process it is necessary to take into account more orbitals (including a complete MCSCF active space) and a larger truer-to-size model of vitamin $B_{12}$ should be used in the calculation according to the needs of today's knowledge of the mechanism of activation.

\section{Conclusions}

There are several possible mechanisms for the intramolecular electron transfer step, including distortion and coupling of orbitals of different symmetries, the possibility of a conical intersection, and a vibronic coupling mechanismall of which are not mutually exclusive. The bond dissociation energy (BDE) for the cobalamin base-off species gives a value of $0.7 \mathrm{eV}$ or $\sim 16 \mathrm{kcal} / \mathrm{mol}$ based on a $\pi^{*}$ ground state potential energy dissociation curve calculated at the B3LYP/ LANL2DZ level and optimized at each Co-C distance; however, this result is considered inaccurate because it is still too large to explain the experimental electrochemical kinetics.

The mechanism describing the bond-breaking of the base-off species in the solvent cage cannot explain the large difference in cleavage rates between reduced $\mathrm{MeCbl}$ and $\mathrm{MeCbi}^{+}$, and $\mathrm{DFT}$ calculations therefore give inaccurate energy barriers in this situation. The alternative methodologies such as open-shell multi-configurational methods in theoretical calculations and perturbation factors along with the bond length estimations and mechanism fitting must be used for studying these processes. 


\section{Acknowledgements}

This research was supported, in part, under National Science Foundation Grants CNS-0958379 and CNS0855217 and the City University of New York High Performance Computing Center at the College of Staten Island and by the National Science Foundation through TeraGrid resources provided by the TeraGrid Science Gateways program under grants CHE090082 and CHE0000036.

\section{References}

1. Sigel, A.; Sigel, H.; Sigel, R.K.O. Eds. Interrelations between Essential Metal Ions and Human Diseases. Metal Ions in Life Sciences 13. Springer, 2013, pp.295-320.

2. Wald, I.; Członkowska, A.; Dowżenko A. Clinical Neurology, Warsaw: National Institute of Medical Publications, 1987, 451 p. (in Polish).

3. Morris, M.C.; Evans, D.A.; Schneider, J.A.; Tangney, C.C.; Bienias, J.L.; Aggarwal, N.T. Dietary folate and vitamins B-12 and B-6 not associated with incident Alzheimer's disease Journal of Alzheimer's Disease, 2006, 9, pp. $435-443$.

4. Siuda, J.; Gorzkowska, A.; Patalong-Ogiewa, M.; Krzystanek, E.; Czech, E.; Wiechuła, B.; Garczorz, W.; Danch, A.; Jasińska-Myga, B.; Opala, G. From mild cognitive impairment to Alzheimer's disease - influence of homocysteine, vitamin B12 and folate on cognition over time: results from one-year follow-up. Polish Journal of Neurology and Neurosurgery, 2009, 43(4), pp. 321-329. (in Polish).

5. Kivipelto, M.; Annerbo, S.; Hultdin, J.; Bäckman, L.; Viitanen, M.; Fratiglioni, L.; Lökk, J. Homocysteine and holo-transcobalamin and the risk of dementia and Alzheimers disease: a prospective study. European Journal of Neurology, 2009, 16, pp. 808-813.

6. Kageyama, M.; Hiraoka, M.; Kagawa, Y. Relationship between genetic polymorphism, serum folate and homocysteine in Alzheimer's disease. Asia-Pacific Journal of Public Health. 2008, 20, Supplement, pp. 111-117.

7. Prodan, C.I.; Cowan, L.D.; Stoner, J.A.; Ross, E.D. Cumulative incidence of vitamin B12 deficiency in patients with Alzheimer disease. Journal of the Neurological Sciences, 2009, 284, pp. 144-148.

8. Li, Y.N.; Gulati, S.; Baker, P.J.; Brody, L.C.; Banerjee, R.; Kruger, W.D. Cloning, Mapping and RNA Analysis of the Human Methionine Synthase Gene. Human Molecular Genetics, 1996, 5, pp. 1851-1858.

9. Voet, J.G.; Voet, D. Biochemistry. J. Wiley \& Sons: New York, 1995, 675 p.

10. Banerjee, R; Ragsdale, S.W. The Many Faces of Vitamin B12: Catalysis by Cobalamin-Dependent Enzymes1. Annual Review of Biochemistry, 2003, 72, pp. 209-247.

11. Scheffold, R.; Abrecht, S.; Ruf, H.-R.; Stamouli, P.; Tinembart, O.; Walder, L.; Weymuth, C. Vitamin B12-mediated electrochemical reactions in the synthesis of natural products Pure and Applied Chemistry, 1987, 59, pp. 363-372.

12. Ogoshi, H.; Kikuchi, Y.; Yamaguchi, T.; Toi, H.; Aoyama, Y. Asymmetric induction in the nucleophilic cyclopropane ring cleavage reaction with vitamin B12s. Organometallics, 1987, 6, pp. 2175-2178.

13. Pattenden, G. Simonsen Lecture. Cobalt-mediated radical reactions in organic synthesis. Chemical Society Reviews, 1988, 17, pp. 361-382.

14. Baldwin, D.A.; Betterton, E.A.; Chemaly, S.M.; Pratt, J.M.J. The chemistry of vitamin B12. Part 25. Mechanism of the $\beta$-elimination of olefins from alkylcorrinoids; evidence for an initial homolytic fission of the Co-C bond Journal of the Chemical Society, Dalton Transactions, 1985, pp. 1613-1618.

15. Baldwin, J.E.;Adlington, R.M.; Kang, T.W. Direct Ring Expansion of Penicillins to 3-Exomethylene Cephalosporins. Tetrahedron Letters, 1991, 48, pp. 7093-7096.

16. Paquette, L. Ed. Encyclopedia of Reagents for Organic Synthesis. Wiley: New York, 1995, pp 5511-5514.

17. Lee, E. R.; Lakomy, I.; Bigler, P.; Scheffold, R. Reductive Radical Cyclisations of Bromo Acetals and (Bromomethyl) silyl Ethers of Terpenoid Alcohols. Helvetica Chimica Acta, 1991, 74, pp. 146-162.

18. Shey, J.; McGinley, C.M.; McCauley, K.M.; Dearth, A.S.; Young, B.T.; van der Donk, W.A. Mechanistic Investigation of a Novel Vitamin B12-Catalyzed Carbon-Carbon Bond Forming Reaction, the Reductive Dimerization of Arylalkenes. Journal of Organic Chemistry, 2002, 67, pp. 837-846.

19. McGinley, C.M.; Relyea, H.A.; van der Donk, W.A. Vitamin B12 Catalyzed Radical Cyclizations of Arylalkenes. Synlett, 2006, pp. 211-214.

20. Banerjee, R. Ed. Chemistry and Biochemistry of $B_{12}$. John Wiley \&Sons: New York, 1999, pp. 73-112.

21. Matthews, R.G. Cobalamin-Dependent Methyltransferases. Accounts of Chemical Research, 2001, 34, pp. 681-689.

22. Banerjee, R. Ed. Chemistry and Biochemistry of $B_{12}$. John Wiley \&Sons: New York, 1999, pp. 681-706.

23. Drennan, C.L.; Huang, S.; Drummond, J.T.; Methews, R.G.; Ludwig, M.L. How a protein binds B12: A 3.0 A X-ray structure of B12-binding domains of methionine synthase. Science, 1994, 266, pp. 1669-1674.

24. Mancia, F.;Keep, N.M.; Nakagawa, A.; Leadlay, P.F.; McSweeney, S.; Rasmussen, B.; Bosecke, P.; Diat, O.; Evans, P.F. How coenzyme B12 radicals are generated: the crystal structure of methylmalonyl-coenzyme A mutase at $2 \AA$ resolution. Structure, 1996,4, pp. 339-350. 
25. Mera, P.E.; Escalante-Semerena, J.C. Multiple roles of ATP: cob(I)alamin adenosyltransferases in the conversion of $\mathrm{B}_{12}$ to coenzyme $\mathrm{B}_{12}$. Applied Microbiology and Biotechnology, 2010, 88, pp. 41-48.

26. Matthews, R.G.; Koutmos, M.; Datta, S. Cobalamin-dependent and cobamide-dependent methyltransferases. Current Opinion in Structural Biology, 2008, 18, pp. 658-666.

27. Koutmos, M.; Datta, S.; Pattridge, K.A.; Smith, J.L.; Matthews, R.G. Insights into the reactivation of cobalamindependent methionine synthase. Proceedings of the National Academy of Sciences, USA, 2009, 106(44), pp. $18527-18532$.

28. Hagemeier, C.H.; Kruer, M.; Thauer, R.K.; Warkentin, E.; Ermler, U. Insight into the mechanism of biological methanol activation based on the crystal structure of the methanol-cobalamin methyltransferase complex. Proceedings of the National Academy of Sciences, USA, 2006, 103(50), pp. 18917-18922.

29. Marsh, E.N.G. Review Article Coenzyme-B12-Dependent Glutamate Mutase. Bioorganic Chemistry, 2000, 28, pp. 176-189.

30. Kräutler, B.; Arigoni, D.; Golding, B.T. Eds. Vitamin B $_{12}$ and the B $_{12}$ proteins. Wiley-VCH: Weinheim, 1998, Chapter 12, pp. 491-504.

31. Babior, B.M.; Carty, T.J.; Abeles, R.H. The mechanism of action of ethanolamine ammonia-lyase, a B12-dependent enzyme. The reversible formation of 5'-deoxyadenosine from adenosylcobalamin during the catalytic process. The Journal of Biological Chemistry, 1974, 249, pp. 1689-1695.

32. Toraya, T. Radical catalysis of B-12 enzymes: structure, mechanism, inactivation, andreactivation of diol and glycerol dehydratases. Cellular and Molecular Life Science, 2000, 57, pp. 106-127.

33. Marsh, E.N.G.; Ballou D.P. Coupling of Cobalt-Carbon bond homolysis and hydrogen atom abstraction in adenosylcobalamin-dependent glutamate mutase. Biochemistry, 1998, 37, pp. 11864-11872.

34. Chowdhury, S.; Banerjee, R. Thermodynamic and kinetic characterization of $\mathrm{Co}-\mathrm{C}$ bond homolysis catalyzed by coenzyme b12-dependent methylmalonyl-CoA mutase. Biochemistry, 2000, 39, pp. 7998-8006.

35. Gruber, K.; Reitzer, R.; Kratky, C. Radical shuttling in a protein: ribose pseudorotation controls alkyl-radical transfer in the coenzyme B12 dependent enzyme glutamate mutase. Angewandte Chemie International Edition, 2001, 40, pp. 3377-3380.

36. Reitzer, R.; Gruber, K.; Jogl, G.; Wagner, U.G.; Bothe, H.; Buckel, W.; Kratky, C. Glutamate mutase from Clostridium cochlearium: the structure of a coenzyme B12-dependent enzyme provides new mechanistic insights. Structure, 1999, 7, pp. 891-902.

37. Kräutler, B.; Arigoni, D.; Golding, B.T. Eds. Vitamin B $_{12}$ and the $B_{12}$ proteins. Wiley-VCH: Weinheim, 1998, Chapter 16, pp. 189-197.

38. Lexa, D.; Savéant, J.-M. Electrochemistry of vitamin $\mathrm{B}_{12}$. 3. One-electron intermediates in the reduction of methylcobalamin and methylcobinamide. Journal of the American Chemical Society, 1978, 100, pp. 3220-3222.

39. Birke, R.L.; Qingdong, H.; Spataru, T.; Gosser, D. K. Jr. Electroreduction of a Series of Alkylcobalamins: Mechanism of Stepwise Reductive Cleavage of the Co-C Bond. Journal of the American Chemical Society, 2006, 128, pp. 1922-1936.

40. Spataru, T.; Birke, R.L. The effect of solvent on the electrode process of methylcobalamine as studied by cyclic voltammetry. Electroanalitical Chemistry, 2006, 593, pp. 74-86.

41. Martin, B.D.; Finke, R.G. Methylcobalamin's Full- vs. Half-Strength Cobalt-Carbon sigma Bonds and Bond Dissociation Enthalpies: $\mathrm{A}>10^{\wedge} 15 \mathrm{Co}-\mathrm{CH}_{3}$ Homolysis Rate Enhancement following One-Antibonding-Electron Reduction of Methlycobalamin. Journal of the American Chemical Society, 1992, 114, pp. 585-592.

42. Kunkely, H.; Vogler, A. Photolysis of methylcobalamin. Nature of the reactive excited state. Journal of Organometallic Chemisctry, 1993, 453, pp. 269-272.

43. Walker, L.A.; II; Jarrett, J.T.; Anderson, N.A.; Pullen, S.H.; Mattews, R.G.; Sension, R.J. Time-Resolved Spectroscopic Studies of B12 Coenzymes: The Identification of a Metastable Cob(III)alamin Photoproduct in the Photolysis of Methylcobalamin. Journal of the American Chemical Society, 1998, 120, pp. 3597-3603.

44. Luo, L.B.; Chen, H.L.; Fu, S.W.; Zhang, S.Y. Laser-induced photoacoustic calorimetric determination of enthalpy and volume changes in photolysis of 5'-deoxyadenosylcobalamin and methylcobalamin. Journal of the Chemical Society, Dalton Transactions, 1998, pp. 2103-2107.

45. Shiang, J.J.; Walker, L.A.; Anderson, N.A.; Cole, A.G.; Sension, R.J. The Time-Resolved Spectroscopic Studies of B12 Coenzymes: The Photolysis of Methylcobalamin Is Wavelength Dependent. Journal of Physical Chemistry B, 1999, 103, pp. 10532-10539.

46. Cole, A.G.; Yoder, L.M.; Shiang, J.J.; Andeson, N.A.; Walker, L.A.; Banaszak Holl, M.M.; Sension, R.J. TimeResolved Spectroscopic Studies of B12 Coenzymes: A Comparison of the Primary Photolysis Mechanism in Methyl-, Ethyl-, n-Propyl-, and 5'-Deoxyadenosylcobalamin. Journal of the American Chemical Society, 2002, 124, pp. 434-438.

47. Hayward, G.C.; Hill, H.A.O.; Pratt, J.M.; Vanston, N.J.; Williams R.J.P. The chemistry of vitamin B12. Part IV. The thermodynamic trans-effect. The Journal of the Chemical Society, 1965, pp. 6485-6493. 
48. Grate, J.H.; Schrauzer, G.N. Chemistry of cobalamins and related compounds. 48. Sterically induced, spontaneous dealkylation of secondary alkylcobalamins due to axial base coordination and conformational changes of the corrin ligand. Journal of the American Chemical Society, 1979, 101, pp. 4601-4611.

49. Halpern, J. Mechanisms of coenzyme B12-dependent rearrangements. Science, 1985, 227, pp. 869-875.

50. Marsh, E.N.G.; Drennan, C.L. Adenosylcobalamin-dependent isomerases: new insights into structure and mechanism. Current Opinion in Chemical Biology, 2001, 5, pp. 499-505.

51. Brown, K.L.; Zou, X.J. Thermolysis of coenzymes B12 at physiological temperatures: activation parameters for cobalt-carbon bond homolysis and a quantitative analysis of the perturbation of the homolysis equilibrium by the ribonucleoside triphosphate reductase from Lactobacillus leichmannii. Inorganic Biochemistry, 1999, 77, pp. 185-195.

52. Dong, S.L.; Padmakumar, R.; Banerjee, R.; Spiro, T.G. Co-C Bond Activation in B12-Dependent Enzymes: Cryogenic Resonance Raman Studies of Methylmalonyl-Coenzyme A Mutase. Journal of the American Chemical Society, 1999, 121, pp. 7063-7070.

53. Bresciana-Pahor, N.; Forcolin, M.; Marzilli, L.G.; Randaccio, L.; Summers, M.F.; Toscano, P.J. Organocobalt B ${ }_{12}$ models: axial ligand effects on the structural and coordination chemistry of cobaloximes. Coordination Chemistry Reviews, 1985, 63, pp. 1-125.

54. Mancia, F.; Evans, P.R. Conformational changes on substrate binding to methylmalonyl CoA mutase and new insights into the free radical mechanism. Structure, 1998, 6, pp. 711-720.

55. Vlasie, M.D.; Banerjee, R. Tyrosine 89 Accelerates Co-Carbon Bond Homolysis in Methylmalonyl-CoA Mutase. Journal of the American Chemical Society, 2003, 125, pp. 5431-5435.

56. Thomä, N.H.; Meier, T.W.; Evans, P.R.; Leadlay, P.F. Stabilization of Radical Intermediates by an Active-Site Tyrosine Residue in Methylmalonyl-CoA Mutase. Biochemistry, 1998, 37, pp. 14386-14393.

57. Toraya, T.; Ishida, A. Acceleration of cleavage of the carbon-cobalt bond of sterically hindered alkylcobalamins by binding to apoprotein of diol dehydrase. Biochemistry, 1988, 27, pp. 7677-7682.

58. Zhu, L.; Kostic, N.M. Molecular orbital study of coenzyme B12. Activation of the cobalt-carbon bond by angular distortions. Inorganic Chemistry, 1987, 26, pp. 4194-4197.

59. Padmakumar, R.; Padmakumar, R.; Banerjee, R. Evidence that Cobalt-Carbon Bond Homolysis is Coupled to Hydrogen Atom Abstraction from Substrate in Methylmalonyl-CoA Mutase. Biochemistry, 1997, 36, pp. 3713-3718.

60. Marsh, E.N.G.; Ballou D.P. Coupling of Cobalt-Carbon Bond Homolysis and Hydrogen Atom Abstraction in Adenosylcobalamin-Dependent Glutamate Mutase. Biochemistry, 1998, 37, pp. 11864-11872.

61. Babior, B.M.; Moss, T.H.; Orme-Johnson, W.H.; Beinert, H. The Mechanism of Action of Ethanolamine AmmoniaLyase, a "B,, -dependent Enzyme. The Journal of Biological Chemistry, 1974, 249, pp. 4537-4544.

62. Licht, S.S.; Booker, S.; Stubbe, J. Studies on the Catalysis of Carbon-Cobalt Bond Homolysis by Ribonucleoside Triphosphate Reductase: Evidence for Concerted Carbon-Cobalt Bond Homolysis and Thiyl Radical Formation. Biochemistry, 1999, 38, pp. 1221-1233.

63. Meier, T.W.; Thomä, N.H.; Evans, P.R.; Leadlay, P.F. Tritium Isotope Effects in Adenosylcobalamin-Dependent Methylmalonyl-CoA Mutase. Biochemistry, 1996, 35, pp. 11791-11796.

64. Chih, H. -W.; Marsh, E.N.G. Pre-Steady-State Kinetic Investigation of Intermediates in the Reaction Catalyzed by Adenosylcobalamin-Dependent Glutamate Mutase. Biochemistry, 1999, 38, pp. 13684-13691.

65. Bandarian, V.; Reed, G.H. Isotope Effects in the Transient Phases of the Reaction Catalyzed by Ethanolamine Ammonia-Lyase: Determination of the Number of Exchangeable Hydrogens in the Enzyme-Cofactor Complex. Biochemistry, 2000, 39, pp. 12069-12075.

66. Kräutler, B.; Arigoni, D.; Golding, B.T. Eds. Vitamin $\mathrm{B}_{12}$ and the $\mathrm{B}_{12}$ proteins. Wiley-VCH: Weinheim, 1998, Chapter 25, pp. 383-402.

67. Barnerjee, R. The Yin-Yang of cobalamin biochemistry. Chemistry \& Biology, 1997, 4, pp. 175-186.

68. Kozlowsky, P.M.; Kuta, J.; Galezowski, W. Reductive Cleavage Mechanism of Methylcobalamin: Elementary Steps of $\mathrm{Co}^{-} \mathrm{C}$ Bond Breaking. The Journal of Physical Chemistry, B, 2007, 111, pp. 7638-7645.

69. Chmielowska, A.; Lodowski, P.; Jaworska, M. Redox Potentials and Protonation of the A-Cluster from AcetylCoA Synthase. A Density Functional Theory Study. The Journal of Physical Chemistry A, 2013, 117, 47, pp. 12484-12496.

70. Kumar, N.; Kuta, J.; Galezowski, W.; Kozlowski, P.M. Electronic Structure of One-Electron-Oxidized Form of the Methylcobalamin Cofactor: Spin Density Distribution and Pseudo-Jahn-Teller Effect. Inorganic Chemistry, 2013, 52, 4, pp. 1762-1771.

71. Kumar, N.; Jaworska, M.; Lodowski, P.; Kumar, M.; Kozlowski, P.M. Electronic Structure of Cofactor-Substrate Reactant Complex Involved in the Methyl Transfer Reaction Catalyzed by Cobalamin-Dependent Methionine Synthase. The Journal of Physical Chemistry B, 2011, 115, pp. 6722-6731.

72. Alfonso-Prieto, M.; Biarnés, X.; Kumar, M.; Rovira, C.; Kozlowski, P.M. Reductive Cleavage Mechanism of 
Co-C Bond in Cobalamin-Dependent Methionine Synthase. The Journal of Physical Chemistry B, 2010, 114, pp. 12965-12971.

73. Jensen, K.P.; Ryde, U. Conversion of Homocysteine to Methionine by Methionine Synthase: A Density Functional Study. Journal of the American Chemical Society, 2003, 125(46), pp. 13970-13971.

74. Kozlowski, P.M.; Kamachi, T.; Kumar, M.; Nakayama, T.; Yoshizawa, K. Theoretical Analysis of the Diradical Nature of Adenosylcobalamin Cofactor-Tyrosine Complex in B12-Dependent Mutases: Inspiring PCET-Driven Enzymatic Catalysis. The Journal of Physical Chemistry B, 2010, 114, pp. 5928-5939.

75. Kumar, M.; Kozlowski, P.M. Role of Tyrosine Residue in the Activation of Co-C Bond in Coenzyme B12Dependent Enzymes: Another Case of Proton-Coupled Electron Transfer? The Journal of Physical Chemistry B, 2009, 113, pp. 9050-9054.

76. Mebs, S.; Henn, J.; Dittrich, B.; Paulmann, C.; Luger, P. Electron Densities of Three B12 Vitamins. The Journal of Physical Chemistry A, 2009, 113, pp. 8366-8378.

77. Chen, S.L.; Blomberg, M.R.; Siegbahn, P.E. How Is a Co-Methyl Intermediate Formed in the Reaction of CobalaminDependent Methionine Synthase? Theoretical Evidence for a Two-Step Methyl Cation Transfer Mechanism. The Journal of Physical Chemistry B, 2011, 115, pp. 4066-4077.

78. Liptak, M.D.; Fleischhacker, A.S.; Matthews, R.G.; Telser, J.; Brunold, T.C. Spectroscopic and Computational Characterization of the Base-off Forms of Cob(II)alamin. The Journal of Physical Chemistry B, 2009, 113, pp. 5245-5254.

79. Kumar, N.; Kozlowski, P.M. Mechanistic Insights for Formation of an Organometallic Co-C Bond in the Methyl Transfer Reaction Catalyzed by Methionine Synthase. The Journal of Physical Chemistry B, 2013, 117, pp. 16044-16057.

80. Kozlowski, P.M.; Kamachi, T.; Kumar, M.; Yoshizawa, K. Reductive elimination pathway for homocysteine to methionine conversion in cobalamin-dependent methionine synthase. Journal of Biological Inorganic Chemistry, 2012, 17, pp. 611-619.

81. Kumar, N.; Alfonso-Prieto, M.; Rovira, C.; Lodowski, P.; Jaworska, M.; Kozlowski, P.M. Role of the Axial Base in the Modulation of the Cob(I)alamin Electronic Properties: Insight from QM/MM, DFT, and CASSCF Calculations. Journal of the Chemical Theory and Computation, 2011, 7, pp. 1541-1551.

82. Reig, A.J.; Conrad, K.S.; Brunold, T.C. Combined Spectroscopic/Computational Studies of Vitamin B12 Precursors: Geometric and Electronic Structures of Cobinamides. Inorganic Chemistry, 2012, 51, pp. 2867-2879.

83. Kobylianskii, I.J.; Widner, F.J.; Kräutler, B.; Chen, P. Co-C Bond Energies in Adenosylcobinamide and Methylcobinamide in the Gas Phase and in Silico. Journal of the American Chemical Society, 2013, 135, pp. 13648-13651.

84. Kepp, K.P. Co-C Dissociation of Adenosylcobalamin (Coenzyme B12): Role of Dispersion, Induction Effects, Solvent Polarity, and Relativistic and Thermal Corrections. The Journal of Physical Chemistry A, 2014, 118, pp. 7104-7117.

85. Kozlowski, P.M.; Kumar, M.; Piecuch, P.; Wei Li, Bauman, N.P.; Hansen, J.A.; Lodowski, P.; Jaworska, M. The cobalt-methyl bond dissociation in methylcobalamin: new benchmark analysis based on density functional theory and completely renormalized coupled-cluster calculations. Journal of the Chemical Theory and Computation, 2012, 8, pp. 1870-1894.

86. Kornobis, K.; Kumar, N.; Wong, B. M.; Lodowski, P.; Jaworska, M.; Andruniow, T.; Ruud, K.; Kozlowski, P. M. Electronically Excited States of Vitamin B12: Benchmark Calculations Including Time-Dependent Density Functional Theory and Correlated ab Initio Methods. The Journal of Physical Chemistry A, 2011, 115, pp. 1280-1292.

87. Lodowski, P.; Jaworska, M.; Kornobis, K.; Andruniow, T.; Kozlowski, P.M. Electronic and Structural Properties of Low-lying Excited States of Vitamin B12. The Journal of Physical Chemistry B, 2011, 115, pp. 13304-13319.

88. Kumar, N.; Liu, S.B.; Kozlowski, P.M. Charge Separation Propensity of the Coenzyme B12-Tyrosine Complex in Adenosylcobalamin-Dependent Methylmalonyl-CoA Mutase Enzyme. The Journal of Physical Chemistry Letters, 2012, 3, pp. 1035-1038.

89. Govender, P.P.; Navizet, I.; Perry, C.B.; Marques, H.M. DFT Studies of Trans and Cis Influences in the Homolysis of the Co-C Bond in Models of the Alkylcobalamins. The Journal of Physical Chemistry A, 2013, 117, pp. 3057-3068.

90. Kozlowski, P.M.; Kamachi, T.; Kumar, M.; Yoshizawa, K. Initial step of B12-dependent enzymatic catalysis: energetic implications regarding involvement of the one-electron-reduced form of adenosylcobalamin cofactor. Journal of Biological Inorganic Chemistry, 2012, 17, pp. 293-300.

91. Kumar, M.; Hirao, H.; Kozlowski, P.M. Co+-H interaction inspired alternate coordination geometries of biologically important cob (I) alamin: possible structural and mechanistic consequences for methyltransferases. Journal of Biological Inorganic Chemistry, 2012, 17, pp. 1107-1121.

92. Jensen, K.P.; Ryde, U. How the Co-C Bond Is Cleaved in Coenzyme B12 Enzymes: A Theoretical Study. Journal of the American Chemical Society, 2005, 127, pp. 9117-9128. 
93. Brunold, T.C.; Conrad, K.S.; Liptak, M.D.; Park, K. Spectroscopically validated density functional theory studies of the B12 cofactors and their interactions with enzyme active sites. Coordination Chemistry Reviews, 2009, 253, pp. 779-794.

94. Li, X.; Chung, L.W.; Paneth, P.; Morokuma, K. DFT and ONIOM(DFT:MM) Studies on Co-C Bond Cleavage and Hydrogen Transfer in B12-Dependent Methylmalonyl-CoA Mutase. Stepwise or Concerted Mechanism? Journal of the American Chemical Society, 2009, 131, pp. 5115-5125.

95. Solheim, H.; Kornobis, K.; Ruud, K.; Kozlowski, P.M. Electronically Excited States of Vitamin B12 and Methylcobalamin: Theoretical Analysis of Absorption, CD, and MCD Data. The Journal of Physical Chemistry B, 2011, 115, pp. 737-748.

96. Kumar, M.; Galezowski, W.; Kozlowski, P.M. Computational modeling of standard reduction potentials of B12 cofactors. International Journal of Quantum Chemistry, 2013, 113, pp. 479-488.

97. Hirao, H. Which DFT Functional Performs Well in the Calculation of Methylcobalamin? Comparison of the B3LYP and BP86 Functionals and Evaluation of the Impact of Empirical Dispersion Correction. The Journal of Physical Chemistry B, 2011, 115, pp. 9308-9313.

98. Park, K.; Brunold, T.C. Combined Spectroscopic and Computational Analysis of the Vibrational Properties of Vitamin B12 in its Co3+, Co2+, and Co1+ Oxidation States. The Journal of Physical Chemistry B, 2013, 117, pp. 5397-5410.

99. Kwiecien, R.A.; Khavrutskii, I.V.; Musaev, D.G.; Morokuma, K.; Banerjee, R.; Paneth, P. Computational Insights into the Mechanism of Radical Generation in B12-Dependent Methylmalonyl-CoA Mutase. Journal of the American Chemical Society, 2006, 128(4), pp. 1287-1292.

100. Banerjee, R.; Dybala-Defratyka, A.; Paneth, P. Quantum catalysis in B12-dependent methylmalonyl-CoA mutase: experimental and computational insights. Philosophical Transactions of the Royal Society of London B, Biological Sciences, 2006, 361(1472), pp. 1333-1339.

101. Kraeutler, B.; Keller, W.; Kratky, C. Coenzyme B12 chemistry: the crystal and molecular structure of cob(II) alamin. Journal of the American Chemical Society, 1989, 111, pp. 8936-8938.

102. Liptak, M.D.; Datta, S.; Matthews, R.G; Brunold, T.C. Spectroscopic Study of the Cobalamin-Dependent Methionine Synthase in the Activation Conformation: Effects of the Y1139 Residue and S-Adenosylmethionine on the B12 Cofactor. Journal of the American Chemical Society, 2008, 130, pp. 16374-16381.

103. Berkovitch, F.; Nicolet, Y.; Wan, J.T.; Jarrett, J.T.; Drennan, C.L. Crystal structure of biotin synthase, an S-adenosylmethionine-dependent radical enzyme. Science, (Washington, DC, United States), 2004, 303, 5654, pp. 76-80.

104. Broach, R.B.; Jarrett, J.T. Role of the [2Fe-2S]2+ Cluster in Biotin Synthase: Mutagenesis of the Atypical Metal Ligand Arginine 260. Biochemistry, 2006, 45, pp. 14166-14174.

105. Jarrett, J.T. The novel structure and chemistry of iron-sulfur clusters in the adenosylmethionine-dependent radical enzyme biotin synthase. Archives of Biochemistry and Biophysics, 2005, 433, pp. 312-321.

106. Spataru, T.; Birke, R.L. Carbon-Cobalt Bond Distance and Bond Cleavage in One-Electron Reduced Methylcobalamin: A Failure of the Conventional DFT Method. The Journal of Physical Chemistry A, 2006, 110, pp. 8599-8604.

107. Bersuker, I.B. Limitations of density functional theory in application to degenerate states. Journal of Computational Chemistry, 1997, 2, pp. 260-267.

108. Bearpark, M.J.; Blancafort, L.; Robb, M.A. Molecular Physics: The pseudo-Jahn-Teller effect: a CASSCF diagnostic. An International Journal at the Interface Between Chemistry and Physics, 2002, 100, pp. 1735-1739. 